\title{
Short communication: Amino trap column improves the separation of methylimidazoles, 5-hydroxymethyl-2-furaldehyde, and sugars in Maillard reaction
}

\author{
Xian-Bing Xu, ${ }^{*}$ Ding-Bo Liu, ${ }^{*}$ Shu-Juan Yu, ${ }^{\dagger}+\ddagger^{1}$ Zhen-Gang Zhao, ${ }^{*}$ and Pei Yu* \\ ${ }^{*}$ College of Light Industry and Food Sciences, South China University of Technology, Guangzhou 510640, China \\ †Guangdong Province Key Laboratory for Green Processing of Natural Products and Product Safety, Guangzhou 510640, China \\ $\ddagger$ State Key Laboratory of Pulp and Paper Engineering, Guangzhou 510640, China
}

\begin{abstract}
A simultaneous analysis of methylimidazoles, reducing sugars, and 5-hydroxymethyl-2-furaldehyde in the Maillard reaction was improved by use of an amino trap column. Analysis was carried out by using highperformance anion exchange chromatography with pulsed amperometric detection (HPAEC-PAD) coupled with an amino trap column. The amino trap column was a useful tool to improve the separation of methylimidazoles, reducing sugars, and 5-hydroxymethyl2 -furaldehyde. This technique is useful for simultaneous analysis of methylimidazoles, reducing sugars, and 5-hydroxymethyl-2-furaldehyde in risk assessment for dairy products.

Key words: 4-methylimidazole, high-performance anion exchange chromatography with pulsed amperometric detection (HPAEC-PAD), Maillard reaction, reducing sugar, 5-hydroxymethyl-2-furaldehyde
\end{abstract}

\section{Short Communication}

The Maillard reaction, also known as the browning reaction, occurs in thermal food processing (Chappel and Howell, 1992; Leonard, 1997; Manzocco et al., 2000). Generally, the Maillard reaction involves the reaction between reducing sugars and amino compounds, which can be described into 3 stages: the early, advanced, and final Maillard reaction steps (Martins et al., 2000; Martins and Van Boekel, 2005; Sandwick et al., 2005). Consequently, a numerous compounds are generated in these stages, including 5-hydroxymethyl2-furaldehyde (HMF; Göğüş et al., 1998; Capuano and Fogliano, 2011) and methylimidazoles (Lee et al., 2012). 5-Hydroxymethyl-2-furaldehyde is known as the degradation product of Amadori rearrangement products via enolization and dehydration reactions (Cammerer

Received February 18, 2014.

Accepted August 4, 2014.

${ }^{1}$ Corresponding author: shujuanyu8@gmail.com et al., 1999; Guan et al., 2012a). In addition, methylimidazoles such as 4-methylimidazole (4-MeI) and 2-methylimidazole (2-MeI) are formed via the reaction between ammonia and $\alpha$-dicarbonyls (methylglyoxal and glyoxal), which are formed via the degradation reaction of carbohydrates (Hengel and Shibamoto, 2013; Jang et al., 2013).

In dairy thermal processes, because of the presence of reducing sugars (lactose and glucose) and amino compounds (including amino acids and proteins), HMF and methylimidazoles are eventually produced via Maillard reaction (Moon and Shibamoto, 2011; Guan et al., 2012b). In addition, methylimidazoles can be introduced into the milk of cows fed ammoniated forage as a result of the interaction of ammonia with reducing sugars (Waagepetersen and Thomsen, 1977). Recently, some studies have reported that potential toxic, mutagenic, and carcinogenic effects were observed after dietary exposure to HMF (Guan et al., 2012c). Meanwhile, 2- and 4-MeI were confirmed as carcinogenic compounds on the basis of animal studies reported by the National Toxicology Program (NTP, Research Triangle Park, NC) and other researchers (Hengel and Shibamoto, 2013; Petruci et al., 2013). Thus, the presence of these harmful compounds (HMF and methylimidazoles) in dairy products indicates that a reliable method for HMF and methylimidazoles analysis should be developed for risk assessment of dairy products.

Traditionally, the separation and analysis of methylimidazoles and HMF was accomplished by reversedphase (RP)-HPLC or gas-liquid chromatography methods (Wilks et al., 1973; Fuschs and Sundell, 1975; Guan et al., 2011; Yamaguchi and Masuda, 2011). However, these methods are not suitable for separation of reducing sugars in samples. Thus, the simultaneous analysis of 4-MeI, 2-MeI, reducing sugar, and HMF by RP-HPLC was impossible. Recently, ion-exchange chromatography as a novel separation technique retaining analyte molecules on the column based on coulombic (ionic) interactions was developed (Clarke et al., 1999; Guignard et al., 2005; Zhang et al., 2012). Ion-exchange 
chromatography can be used for almost any type of charged molecule, including reducing sugars and amino acids. In this experiment, the target analytes, including methylimidazoles, HMF, and reducing sugars (acid dissociation constant, $\mathrm{p} K_{\mathrm{a}}$, values of the imidazole ring and HMF were 7.70 and 12.82, respectively) were relatively transformed into anionic forms in alkaline solution. Thus, the simultaneous analysis of 4-MeI, 2-MeI, reducing sugars, and HMF by ion exchange chromatography should be an option. However, to the best of our knowledge, the simultaneous analysis of 4-MeI, 2-MeI, reducing sugars, and HMF is rarely reported in the literature.

Reducing sugars, 4-MeI, 2-MeI, and HMF were purchased from Sigma-Aldrich Chemical Co. (St. Louis, MO). Sodium hydroxide (50\%) was of HPLC grade and purchased from Merck (Darmstadt, Germany).

The samples were filtered through a Millex-HN nylon clarification kit of $0.45-\mu \mathrm{m}$ pore size (Millipore, Bedford, MA), and analyzed on a DX 5000 Dionex system (Dionex Corp., Sunnyvale, CA), with a gradient pump (model EG40) with on-line degassing, and an integrated pulsed amperometric electrochemical detector (PAD, model ED40, Dionex Corp.). Separation was accomplished on an amino trap column $(4 \times 50 \mathrm{~mm})$ coupled with a CarboPac PA1 analytical column $(2 \times$ $250 \mathrm{~mm}$; Dionex Corp.) using isocratic elution (100 $\mathrm{mmol} / \mathrm{L} \mathrm{NaOH}$ ) for $60 \mathrm{~min}$. All tests used a constant flow rate of $0.25 \mathrm{~mL} / \mathrm{min}$. The injection volume was 20 $\mu \mathrm{L}$. The $\mathrm{pH}$ reference electrode (061879, Dionex Corp.) and gold working electrode (061875, Dionex Corp.) were used in amino trap column with pulsed integrated amperometric electrochemical detector analysis. The waveforms were applied under the following settings: $\mathrm{E}_{1}=0.13 \mathrm{~V}\left(\mathrm{t}_{1}=0.04 \mathrm{~s}\right), \mathrm{E}_{2}=0.33 \mathrm{~V}\left(\mathrm{t}_{2}=0.16 \mathrm{~s}\right), \mathrm{E}_{3}$ $=0.55 \mathrm{~V}\left(\mathrm{t}_{3}=0.24 \mathrm{~s}\right), \mathrm{E}_{4}=0.33 \mathrm{~V}\left(\mathrm{t}_{4}=0.09 \mathrm{~s}\right), \mathrm{E}_{5}=$ $-1.67 \mathrm{~V}\left(\mathrm{t}_{5}=0.01 \mathrm{~s}\right), \mathrm{E}_{6}=0.93 \mathrm{~V}\left(\mathrm{t}_{6}=0.01 \mathrm{~s}\right), \mathrm{E}_{7}=$ $0.13 \mathrm{~V}\left(\mathrm{t}_{7}=0.01 \mathrm{~s}\right)$, where $\mathrm{E}_{\mathrm{n}}$ is the applied voltage on work electrode, and $t_{n}$ is the duration of the applied voltage. Integration occurred from 0.20 to $0.44 \mathrm{~s}$ during $\mathrm{E}_{3}$ application.

The $\mathrm{pH}$ value of eluent was an important factor in dissociation of $4-\mathrm{MeI}$ and 2 -MeI. At $\mathrm{pH}$ values greater than the $\mathrm{p} K_{\mathrm{a}}$ of the amino group (about 14.83), nitrogen was predominantly protonated as a negative charged imino group. As shown in Figure 1, 4-MeI and 2-MeI were separated on a CarboPac PA1 anion exchange column. The peaks of 4-MeI and 2-MeI were not symmetrical and had a long tail at low concentrations of eluent (e.g., 25 or $75 \mathrm{mmol} / \mathrm{L} \mathrm{NaOH}$ ). However, the peaks of $4-\mathrm{MeI}$ and 2-MeI were symmetrical and narrow at $100 \mathrm{mmol} / \mathrm{L} \mathrm{NaOH}$. One proposed explanation was that 4 -MeI and 2-MeI may be fully transformed

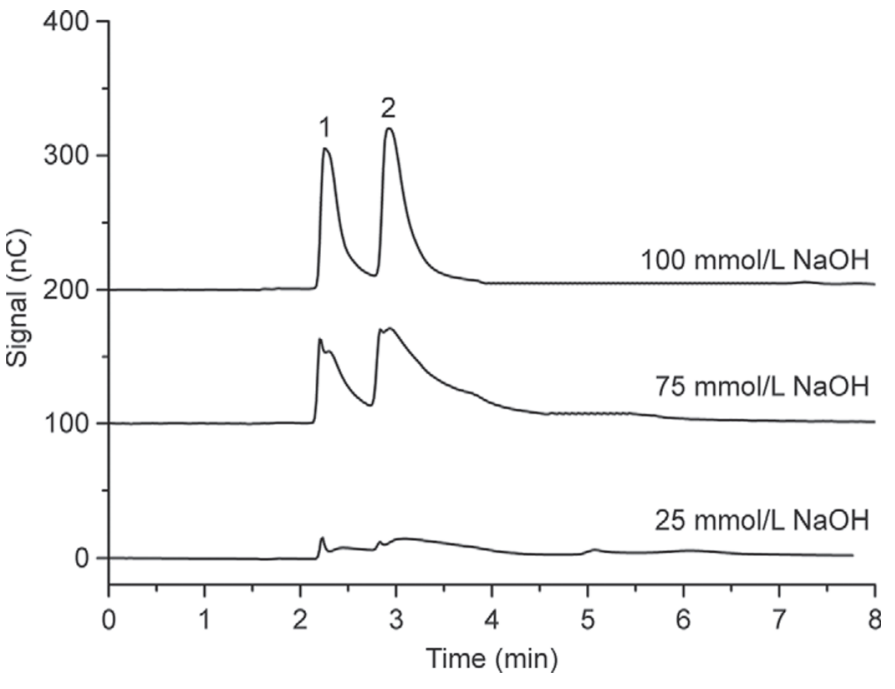

Figure 1. The separation of methylimidazoles (MeI) on a CarboPac PA1 anion exchange column (Dionex Corp., Sunnyvale, CA) without amino trap column affected by the concentration of $\mathrm{NaOH}$. The y-axis indicates the signal in nanocoulombs $(\mathrm{nC})$; peaks 1 and 2 represent 2-MeI and 4-MeI, respectively.

into the anionic forms at high concentrations of alkaline solution.

Glucose, mannose, maltose, 2-MeI, 4-MeI, and HMF always have different charges and could be retained by anion exchange column. As shown in Figure 2, glucose, mannose, maltose, 2-MeI, 4-MeI, and HMF could be detected by PAD. However, it was difficult to separate glucose, mannose, and HMF on a CarboPac PA1 anion exchange column. Meanwhile, 2-MeI and 4-MeI (retention time $<8 \mathrm{~min}$ ) were weakly retained on the CarboPac PA1 anion exchange column. Therefore, the CarboPac PA1 anion exchange column was not suitable for simultaneous detection of glucose, mannose, maltose, 2-MeI, 4-MeI, and HMF.

When a CarboPac PA1 anion exchange columnPAD combined with an amino trap column was used to improve separation and determination, glucose, mannose, maltose, 2-MeI, 4-MeI, and HMF could be fully separated and detected simultaneously (Figure 3). Documentation from Dionex (Document No. 03119705) stated that the amino trap column was packed with $10-\mu \mathrm{m}$, high-capacity anion exchange resin that had high selectivity for hydrophobic amino compounds relative to monosaccharides, using hydroxide eluents. Therefore, the retention of $2-\mathrm{MeI}, 4-\mathrm{MeI}$, and $\mathrm{HMF}$ (retention times were 11.5, 20.8, and $49.5 \mathrm{~min}$, respectively) were greatly improved by the amino trap column. However, the retention times of reducing sugars were changed slightly. Meanwhile, the peak shape of all target analytes was symmetrical and narrow. Thus, the CarboPac PA1 anion exchange column-PAD with 
6812

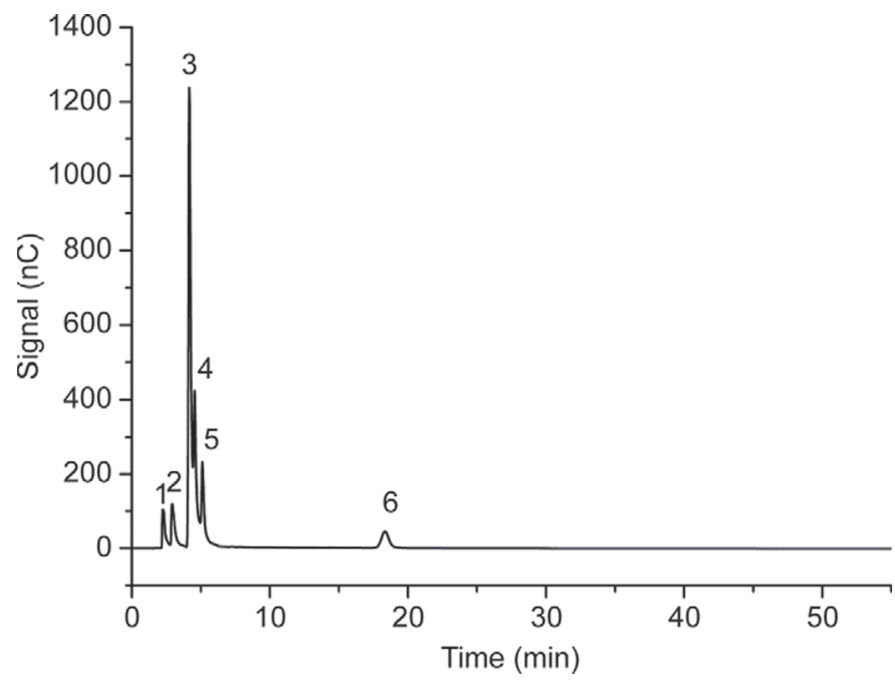

Figure 2. Analysis of methylimidazoles (MeI), reducing sugars, and 5-hydroxymethyl-2-furaldehyde (HMF) by high-performance anion exchange chromatography-electrochemical detector (CarboPac PA1 anion exchange column; Dionex Corp., Sunnyvale, CA) without amino trap column. The y-axis indicates the signal in nanocoulombs (nC); peaks 1, 2, 3, 4, 5, and 6 represent 2-MeI, 4-MeI, HMF, glucose, mannose, and maltose, respectively.

the amino trap column was suitable for simultaneous detection of glucose, mannose, maltose, 2-MeI, 4-MeI, and HMF.

Calibration curves were generated from calibration standards (HMF and maltose ranging from 1 to 100 $\mathrm{mg} / \mathrm{L}$; methylimidazoles, glucose, and mannose ranging from 0.1 to $10 \mathrm{mg} / \mathrm{L}$ ). As shown in Table 1, calibration equations of all target analytes had excellent linearity. On the other hand, the limit of quantification (LOQ) was determined as 10 times the observed signal-to-noise ratio. In this experiment, as shown in Figure 3, the LOQ of glucose, mannose, maltose, HMF, 4-MeI, and 2 -MeI were $0.02,0.02,0.10,0.10,0.02$, and $0.02 \mathrm{mg} / \mathrm{L}$, respectively. These results indicate that HPAEC-PAD coupled with an amino trap column is suitable for
XU ET AL.

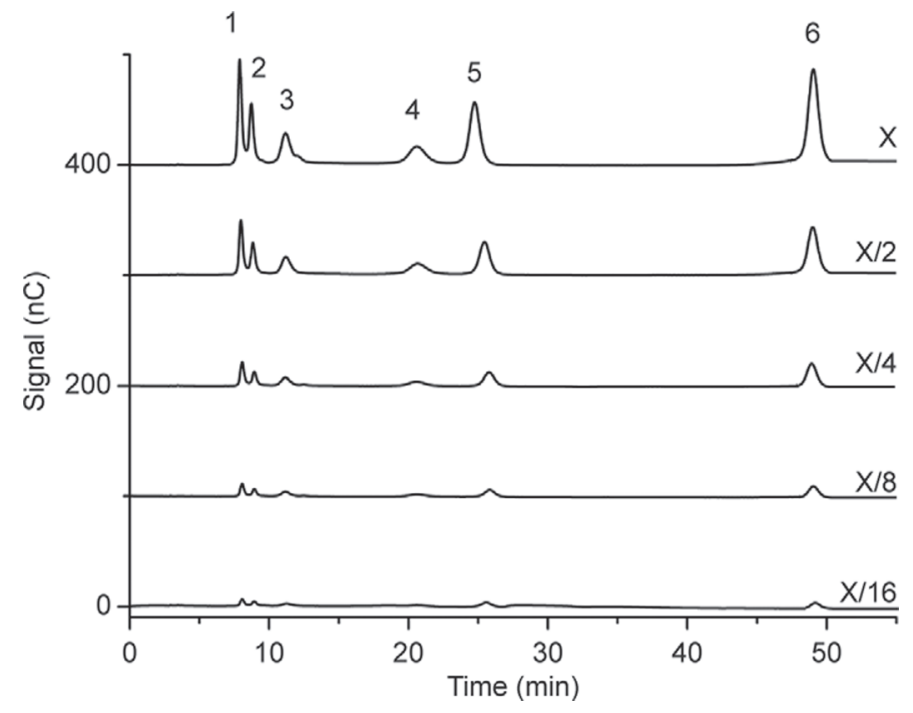

Figure 3. Analysis of methylimidazoles (MeI), reducing sugars, and 5-hydroxymethyl-2-furaldehyde (HMF) by high-performance anion exchange chromatography-electrochemical detector (CarboPac PA1 anion exchange column; Dionex Corp., Sunnyvale, CA) with amino trap column. X represents the concentration of standard sample $(1.25 \mathrm{mg} / \mathrm{L}$ for methylimidazoles, glucose, and mannose; $5 \mathrm{mg} / \mathrm{L}$ for HMF and maltose). The y-axis indicates the signal in nanocoulombs (nC); peaks 1, 2, 3, 4, 5 and 6 represent glucose, mannose, 2-MeI, 4-MeI, maltose, and HMF, respectively.

simultaneous analysis of reducing sugars, methylimidazoles, and HMF at trace concentrations.

In conclusion, an amino trap column improved the separation of methylimidazoles, reducing sugars, and HMF performed using an HPAEC-PAD system with a CarboPac PA1 anionic exchange column. The limit of detection for methylimidazoles and reducing sugars was $0.02 \mathrm{mg} / \mathrm{L}$, whereas that for maltose and HMF was $0.1 \mathrm{mg} / \mathrm{L}$ using HPAEC-PAD. Therefore, simultaneous analysis of reducing sugars, methylimidazoles, and HMF at trace concentration by ion exchange chromatography is a valid and inexpensive choice for a small laboratory.

Table 1. Linear calibration ranges and regression equations of analytes as measured by amino trap column with pulsed integrated amperometric electrochemical detector (AMTC-PAD)

\begin{tabular}{lclcc}
\hline Analyte $^{1}$ & $\begin{array}{c}\text { Calibration range } \\
(\mathrm{mg} / \mathrm{L})\end{array}$ & Regression equation & & $\mathrm{R}^{2}$ \\
\hline $\mathrm{HMF}$ & $1.0-100.0$ & $\mathrm{y}=2.493 \mathrm{x}+3.891$ & 0.998 & 2.10 \\
4-MeI & $0.1-10.0$ & $\mathrm{y}=16.480 \mathrm{x}+0.479$ & 0.997 & 1.27 \\
2-MeI & $0.1-10.0$ & $\mathrm{y}=9.354 \mathrm{x}+0.470$ & 0.999 & 1.73 \\
Glucose & $0.1-100.0$ & $\mathrm{y}=27.26 \mathrm{x}-0.112$ & 0.998 & 2.34 \\
Mannose & $0.1-100.0$ & $\mathrm{y}=19.45 \mathrm{x}+0.062$ & 0.998 & 3.15 \\
Maltose & $1.0-100.0$ & $\mathrm{y}=10.97 \mathrm{x}-0.809$ & 0.998 & 2.16 \\
\hline
\end{tabular}

${ }^{1} \mathrm{HMF}=$ 5-hydroxymethylfurfural; 4-MeI = 4-methylimidazole; 2-MeI = 2-methylimidazole

${ }^{2}$ Where $\mathrm{y}=$ peak area of analytes $(\mathrm{nC} \times \min )$, where $\mathrm{nC}=$ nanocoulomb, and $\mathrm{x}=$ concentration of analytes $(\mathrm{mg} / \mathrm{L})$.

${ }^{3}$ Relative standard deviation. 


\section{ACKNOWLEDGMENTS}

All authors acknowledge the National Science Foundation of China (Grant no. 31271889; Beijing, China), the basic research foundation of SCUT (2014ZP0019, Guangzhou, China) and the Science and Technology Planning Project of Guangdong Province (No.2011B050400035, Guangzhou, China) for financial support.

\section{REFERENCES}

Cammerer, B., B. L. Wedzicha, and L. W. Kroh. 1999. Nonenzymatic browning reactions of retro-aldol degradation products of carbohydrates. Eur. Food Res. Technol. 209:261-265.

Capuano, E., and V. Fogliano. 2011. Acrylamide and 5-hydroxymethylfurfural (HMF): A review on metabolism, toxicity, occurrence in food and mitigation strategies. Lebenson. Wiss. Technol. 44:793810

Chappel, C. I., and J. C. Howell. 1992. Caramel colours-A historical introduction. Food Chem. Toxicol. 30:351-357.

Clarke, A. P., P. Jandik, R. D. Rocklin, Y. Liu, and N. Avdalovic. 1999. An integrated amperometry waveform for the direct, sensitive detection of amino acids and amino sugars following anionexchange chromatography. Anal. Chem. 71:2774-2781.

Fuschs, G., and S. Sundell. 1975. Quantitative determination of 4-methylimidazole as 1-acetyl derivative in caramel color by gas-liquid chromatography. J. Agric. Food Chem. 23:120-122.

Göğüş, F., H. Bozkurt, and S. Eren. 1998. Nonenzymic browning reactions in multi sugar and amino acid systems. J. Food Process. Preserv. 22:81-90.

Guan, Y.-G., W.-H. Shi, S.-J. Yu, and X.-B. Xu. 2011. Ultrafiltration of caramel color solutions reduces 5-hydroxymethyl-2-furaldehyde. J. Membr. Sci. 380:9-12.

Guan, Y.-G., S.-L. Wang, S.-J. Yu, S.-M. Yu, and Z.-G. Zhao. 2012a. Changes in the initial stages of a glucose-proline Maillard reaction model system influences dairy product quality during thermal processing. J. Dairy Sci. 95:590-601.

Guan, Y. G., S. L. Wang, S. J. Yu, S. M. Yu, and Z. G. Zhao. 2012b. Changes in the initial stages of a glucose-proline Maillard reaction model system influences dairy product quality during thermal processing. J. Dairy Sci. 95:590-601.

Guan, Y.-G., P. Yu, S.-J. Yu, X.-B. Xu, and X.-L. Wu. 2012c. Short communication: Simultaneous analysis of reducing sugars and 5-hydroxymethyl-2-furaldehyde at a low concentration by high performance anion exchange chromatography with electrochemical detector, compared with HPLC with refractive index detector. J. Dairy Sci. 95:6379-6383. http://dx.doi.org/10.3168/jds.20125623.
Guignard, C., L. Jouve, M. B. Bogéat-Triboulot, E. Dreyer, J.-F. Hausman, and L. Hoffmann. 2005. Analysis of carbohydrates in plants by high-performance anion-exchange chromatography coupled with electrospray mass spectrometry. J. Chromatogr. A 1085:137-142.

Hengel, M., and T. Shibamoto. 2013. Carcinogenic 4(5)-methylimidazole found in beverages, sauces, and caramel colors: Chemical properties, analysis, and biological activities. J. Agric. Food Chem. 61:780-789.

Jang, H. W., Y. Jiang, M. Hengel, and T. Shibamoto. 2013. Formation of 4(5)-methylimidazole and its precursors, $\alpha$-dicarbonyl compounds in Maillard model systems. J. Agric. Food Chem. 61:6865-6872.

Lee, K.-G., H. Jang, and T. Shibamoto. 2012. Formation of carcinogenic 4(5)-methylimidazole in caramel model systems: A role of sulfite. Food Chem. 136:1165-1168.

Leonard, N. B. 1997. Maillard reaction as influenced by buffer type and concentration. Food Chem. 59:143-147.

Manzocco, L., S. Calligaris, D. Mastrocola, M. C. Nicoli, and C. R. Lerici. 2000. Review of non-enzymatic browning and antioxidant capacity in processed foods. Trends Food Sci. Technol. 11:340-346.

Martins, S., and M. Van Boekel. 2005. A kinetic model for the glucose/ glycine Maillard reaction pathways. Food Chem. 90:257-269.

Martins, S. I. F. S., W. M. F. Jongen, and M. A. J. S. van Boekel. 2000. A review of Maillard reaction in food and implications to kinetic modelling. Trends Food Sci. Technol. 11:364-373.

Moon, J.-K., and T. Shibamoto. 2011. Formation of carcinogenic 4(5)-methylimidazole in Maillard reaction systems. J. Agric. Food Chem. 59:615-618.

Petruci, J. F. S., E. A. Pereira, and A. A. Cardoso. 2013. Determination of 2-methylimidazole and 4-methylimidazole in caramel colors by capillary electrophoresis. J. Agric. Food Chem. 61:2263-2267.

Sandwick, R., M. Johanson, and E. Breuer. 2005. Maillard reactions of ribose 5-phosphate and amino acids. Ann. N. Y. Acad. Sci. 1043:85-96.

Waagepetersen, J., and K. V. Thomsen. 1977. Effect on digestibility and nitrogen content of barley straw of different ammonia treatments. Anim. Feed Sci. Technol. 2:131-142.

Wilks, R. A., Jr., A. J. Shingler, L. S. Thurman, and J. S. Warner. 1973. The isolation of 4-methylimidazole from caramel color and its determination by thin-layer and gas-liquid chromatography. J. Chromatogr. A 87:411-418.

Yamaguchi, H., and T. Masuda. 2011. Determination of 4(5)-methylimidazole in soy sauce and other foods by LC-MS/MS after solidphase extraction. J. Agric. Food Chem. 59:9770-9775.

Zhang, Z., N. M. Khan, K. M. Nunez, E. K. Chess, and C. M. Szabo. 2012. Complete monosaccharide analysis by high-performance anion-exchange chromatography with pulsed amperometric detection. Anal. Chem. 84:4104-4110. http://dx.doi.org/10.1021/ ac300176z. PubMed 